\title{
A literatura infantil e a formaçáo de conceitos matemáticos nos primeiros anos de escolarizaçáo
}

Laudelina Braga*

Norivan L. L. Dutra**

\section{Resumo}

Este artigo se propóe a discutir as vantagens da interdisciplinaridade entre Matemática e literatura infantil, visto que grande parte das razóes para o mito de que a Matemática é uma disciplina complexa e abstrata se deve ao fato de que o modelo de ensino adotado por muitos professores se baseia essencialmente na transmissão, repetição e memorização de regras. No entanto, os resultados são muito melhores quando, conforme recomendado pelos Parâmetros Curriculares Nacionais (1997), os professores ensinam a matemática partindo de situaçôes próprias do universo infantil. A literatura infantil oferece a oportunidade de relacionar situaçóes do cotidiano dos alunos com a aprendizagem de diversos conceitos, inclusive de conceitos matemáticos.

Palavras-chave: interdisciplinaridade, Matemática, literatura infantil.

\section{Children's literature and the formation of mathematics concepts during the early years of schooling}

\begin{abstract}
This paper discusses the advantages of interdisciplinarity between Mathematics and children's literature seeing that many reasons for the myth that Mathematics is a complex abstract subject are due to the fact that the teaching model adopted by many teachers is essentially based on the transmission, repetition and memorization of rules. However, results are far better when teachers teach mathematics using situations which are specific to the children's world, as recommended by the National Curriculum Parameters (1997). Children's literature provides an opportunity for relating the everyday activities of students with the learning of different concepts, including those of mathematics.
\end{abstract}

Keywords: interdisciplinarity, Mathematics, children's literature.

\footnotetext{
* Mestranda em Educação pela FE/UFG. Docente no Instituto Federal de Goiás - Campus Uruaçu. E-mail: linnabraga@hotmail.com

** Mestranda em Educação pela FE/UFG. E-mail: nolisud@yahoo.com.br
} 


\section{Introdução}

O baixo índice de aproveitamento dos alunos em Matemática nas escolas brasileiras - desde os anos iniciais - é acentuado no percurso da escolaridade, especialmente quando se faz presente o mito de que essa disciplina é complexa e de difícil compreensão. Nessa discussão, os Parâmetros Curriculares Nacionais (PCN) afirmam ser notório que "em relação ao ensino de Matemática há problemas antigos e novos a serem enfrentados e resolvidos" (BRASIL/PCN, 1998c, p. 24), já que, de acordo com o programa Todos pela Educação (BRASIL, 2012), os resultados da Prova ABC (Avaliação Brasileira do Final do Ciclo de Alfabetização, 2011) expressam dados preocupantes e que demandam uma série de estudos e alternativas de intervenção a essa problemática. Tais dados afirmam que os alunos do $3^{\circ}$ ano do Ensino Fundamental apresentam mais dificuldades em Matemática do que em leitura - apenas $42 \%$ deles dominam a adição e a subtração e conseguem solucionar problemas envolvendo, por exemplo, notas e moedas.

De acordo com os estudos de Sanchez (2004, p. 174), as dificuldades na Matemática estão relacionadas com o "alto nível de abstração, generalização e complexidade dos conceitos e algoritmos". Assim, tornase crucial a análise das dificuldades que paulatinamente acompanham a resolução de problemas. Nesse sentido, Sanchez pontua que as dificuldades de resoluçóes

implicam a compreensão do problema, compreensão e habilidade para analisar o problema e raciocinar matematicamente [...]; dificuldades atencionais e motivacionais; dificuldades na memória etc. [...]. Dificuldades originadas no ensino inadequado ou insuficiente, seja porque a organização do mesmo não está bem sequenciada, ou não se proporcionam elementos de motivaçấo suficientes; seja porque os conteúdos não se ajustam às necessidades e ao nível de desenvolvimento do aluno, ou não estão adequados ao nível de abstração, ou não se treinam as habilidades prévias; seja porque a metodologia é muito pouco motivadora e muito pouco eficaz. (SANCHEZ, 2004, p. 174)

Nesse contexto, várias alternativas têm sido desenvolvidas, a fim de promover discussóes em torno do processo ensino e aprendizagem da Matemática, bem como dos desafios e das possibilidades didáticometodológicas para esta área de conhecimento. E por que não iniciar de 
imediato essa discussão na Educação Infantil, já que essa etapa constitui o primeiro espaço formal do contato das crianças com as noçôes e os conceitos matemáticos? Há, de antemão, uma urgente necessidade de refletir e discutir o ensino da Matemática, como área de conhecimento organizada, mediante a elaboração dos conceitos matemáticos escolares a partir da relação ensino e aprendizagem, da relação aluno-aluno e da relação aluno-situaçóes-cotidianas.

Para discutir essa problemática, é necessário inicialmente um estudo do conceito da interdisciplinaridade na sala de aula e de como o Referencial Curricular Nacional para Educação Infantil (RCNEI) para educação infantil direciona este trabalho. Logo após, apresenta-se a discussão do trabalho interdisciplinar envolvendo a literatura desenvolvida nos primeiros anos da escolarização e a formação dos conceitos matemáticos na Educação Infantil. Em seguida, há sugestôes de livros literários que podem ser utilizados de forma interdisciplinar com os conceitos matemáticos, tendo como exemplo o livro As centopeias e os seus sapatinhos (CAMARGO, 1991).

\section{A interdisciplinaridade na sala de aula}

O estudo sobre a interdisciplinaridade é recente no Brasil; começou na década de 1960 e, nos anos 1970, o epistemólogo Hilton Japiassu, influenciado por Georges Gusdorf, publicou o primeiro livro sobre o tema: Interdisciplinaridade e patologia do saber. Nessa mesma década, aparece Ivani Fazenda (1976) e, nos anos 1980, surgem autores como Gusdorf, Apostel, Bottomore, Dufrenne, Mommsen, Morin, Palmarini, Smirnov, entre outros, que também desenvolveram essa temática (FAZENDA, 1999).

Mas foi na década de 1990 que houve "uma verdadeira explosão de trabalhos sobre a questão da interdisciplinaridade", afirma Neuenfeldt (2006). Nesse período (1990), podem ser encontrados textos que apresentam como elemento central a interdisciplinaridade e suas relaçóes metodológicas, na "Educação Infantil (JUNQUEIRA FILHO, 1996), no Ensino Fundamental (SAMPAIO et al. 1994; SILVA; SOUZA, 1995), no Ensino Médio (SAMPAIO et al. 1994), bem como na Educaçáo Superior (PETRAGLIA, 1993)". Nessa década, também se encontram discussóes sobre "os fundamentos didático-pedagógicos da interdisciplinaridade (LÜCK, 1994; FAZENDA, 1994, 1998), o que inaugurou um novo modo 
de debate sobre práticas interdisciplinares na escola (FAZENDA, 1991a, 1995)" (GARCIA, 2008, p. 367).

Segundo Neuenfeldt (2006), apesar de existirem estudos e pesquisas desenvolvidos sobre essa temática, o conceito de interdisciplinaridade ainda não é único e estável. No entanto, Japiassu (1976, p. 74) a caracteriza como "a intensidade das trocas entre os especialistas e pelo grau de interação real das disciplinas no interior de um mesmo projeto de pesquisa"; em outras palavras, "é uma forma de trabalhar em sala de aula, na qual se propóe um tema com abordagens em diferentes disciplinas. É compreender, entender as partes de ligação entre as diferentes áreas de conhecimento, unindo-se para transpor algo inovador, abrir sabedorias" e também "resgatar possibilidades e ultrapassar o pensar fragmentado". Assim, com um tema para estudo, os professores discutem e elaboram propostas de atividades envolvendo as diferentes áreas de conhecimento que apresentam certa correlação. O tema passa a "conversar" e se complementar a partir dos enfoques diversificados, e aí não há a compartimentalização dos saberes de forma estática, mas mediante o trabalho interdisciplinar, há um dinamismo da aprendizagem e consequentemente o enriquecimento das situaçóes de aprendizagem (NEUENFELDT, 2006, p. 7).

Nessa perspectiva, o Referencial Curricular Nacional para Educação Infantil (RCNEI) aponta diretrizes para o trabalho pedagógico na educação infantil: "os conteúdos devem ser trabalhados de forma integrada, relacionados entre si" (BRASIL/RCNEI, 1998a, p. 54), para que sejam proporcionadas às crianças condiçóes de "conhecerem, descobrirem e ressignificarem novos sentimentos, valores, ideias, costumes e papéis sociais" (BRASIL/RCNEI, 1998b, p. 11). Para isso, a organização dos conteúdos foi estabelecida sob dois critérios - âmbito e eixo -, os quais foram pensados mediante as particularidades de cada faixa etária - zero a seis anos - e as formas específicas de aprendizagem de cada criança.

O primeiro critério de organização é compreendido "como domínio ou campo de açấo que dáo visibilidade aos eixos de trabalho educativo para que o professor possa organizar sua prática educativa e refletir sobre a abrangência das experiências que propicia às crianças". Já o segundo referese ao desenvolvimento do trabalho e abrange "movimento, artes visuais, música, linguagem oral e escrita, natureza e sociedade e matemática" (BRASIL/RCNEI, 1998a, p. 45 e 46). A metodologia pedagógica citada pelo RCNEI diz que a integração do conteúdo "possibilita que a realidade 
seja analisada por diferentes aspectos, sem fragmentá-la”. Nesse contexto, escolas e professores devem favorecer um ambiente propício ao aprendizado por meio das brincadeiras, do faz de conta, da linguagem e da expressão corporal (p. 54).

Segundo o RCNEI (1998b), por meio das brincadeiras, as crianças desenvolvem capacidades "tais como a atenção, a imitação, a memória, a imaginação". A fantasia e a imaginação também "são elementos fundamentais para que elas aprendam mais sobre a relação entre as pessoas, sobre o eu e sobre o outro" e o faz de conta proporciona o "imitar, imaginar, representar e o comunicar de uma forma específica que uma coisa pode ser outra, que uma pessoa pode ser uma personagem, que uma criança pode ser um objeto ou um animal, que um lugar 'faz de conta' que é outro" e assim sucessivamente (BRASIL/RCNEI, 1998b, p. 22 e 23).

Para Abramovich (1997), essas capacidades e possibilidades de aprendizado estão intimamente ligadas ao potencial da literatura infantil, pois, para ela, o "ouvir histórias pode estimular o desenhar, o musicar, o sair, o pensar, o teatrar, o imaginar, o brincar, o ver o livro, o escrever, o querer ouvir de novo" (ABRAMOVICH, 1997, p. 23). Ao "ler uma história, a criança também desenvolve todo o potencial crítico. A partir daí, ela pode pensar, duvidar, perguntar, questionar querendo saber mais e melhor" (p. 141). Nesse sentido, pode-se constatar que a história permite a aprendizagem prazerosa e significativa como bem afirma a autora:

É através duma história que se podem descobrir outros lugares, outros tempos, outros jeitos de agir e de ser, outra ética, outra ótica [...]. É ficar sabendo História, Geografia, Filosofia, Política, Sociologia, sem precisar saber o nome disso tudo e muito menos achar que tem cara de aula [...] porque, se tiver, deixa de ser literatura, deixa de ser prazer e passa a ser didática, que é outro departamento (não tão preocupado em abrir as portas da compreensão do mundo). (ABRAMOVICH, 1997, p. 17)

Dessa maneira, a literatura infantil, um recurso didático-metodológico balizador, oferece inúmeras possibilidades para se trabalhar em sala de aula - talvez envolvendo uma, duas ou todas as disciplinas de cada nível de ensino ao mesmo tempo, num mesmo projeto. Segundo Smole (2000), por meios das histórias, as crianças farão conexóes entre o real e o imaginário e desenvolveráo habilidades como a ordenação do pensamento. Além disso, perceberão a noção de tempo e espaço, de quantidade, tamanho e espessura, 
em cima e em baixo, criarão estratégias para a resolução de problemas, farão relaçóes entre a representação numérica e a quantidade, entre outras habilidades que serão essenciais para a compreensão da matemática, pois são habilidades e competências que podem ser desenvolvidas por meio das brincadeiras, das histórias infantis, do faz de conta, das parlendas, da leitura de imagens e do próprio imaginário das crianças.

\section{A literatura e a matemática na educaçáo infantil}

Ao pensar na Educação Infantil como espaço formal que propicia às crianças o contato com a sistematização dos saberes matemáticos, devemse discutir as tendências e teorias pedagógicas que são determinantes na organização da relação entre ensino e aprendizagem. Assim, em uma visão tradicionalista de ensino, o professor apenas transmite esses saberes acumulados culturamente de geração em geração e, mediante uma rotina primada pelo treino e pela repetição, a criança é preparada e moldada para repetir esses saberes tal como recebeu. Nessa visão, a Matemática é considerada como algo pronto e acabado, não são planejados, entáo, situaçóes de ensino em que a criança construa, matematicamente, os saberes e conhecimentos a partir das situaçóes e vivências da sala de aula e do seu cotidiano (ROSA, 2009).

Nessa concepção, a Matemática é vista, na maioria das vezes, como a área do conhecimento que apenas "transmite uma série de regras arbitrárias e ensina uma linguagem de signos, sem garantir o desenvolvimento das estruturas cognitivas que sustentem a possibilidade do real entendimento do que se pretende ensinar" (ROSA, 2009, p. 5). Dessa forma, os saberes relacionados à Matemática não se integram com as açôes do cotidiano dos alunos, com o propósito de solucionar os problemas da vida; antes, "o ensino é quase que todo centrado em memorização de regras e na aprendizagem de 'truques' através dos quais não se obtém a compreensão dos porquês, mas se tem de utilizá-los porque 'funcionam', e a avaliação escolar é superficial e mecânica" (CARRAHER 1982 apud ROSA, 2009, p. 5).

Na teoria construtivista, a criança é vista como um sujeito capaz de construir e elaborar seus próprios saberes e conhecimentos mediados pelo espaço social em que está inserida, pelo mundo, pelos objetos, pelas cores, pelo imaginário infantil e, portanto, pela literatura infantil. Segundo Piaget (1974), o ensino deveria formar o raciocínio, conduzindo ao entendimento 
das situações de aprendizagem e não apenas à memorização, o ensino deveria desenvolver o espírito criativo e não o repetitivo.

Entretanto, quando o ensino da Matemática é pensado e organizado com base na concepção sociointeracionista, as situações do espaço escolar promovem indiscutivelmente a "sociabilidade e possibilitam aprendizagens significativas [...] Tanto o professor quanto os alunos que já dominam uma dada função são agentes de desenvolvimento dos demais" (OLIVEIRA, 1997, p. 98). Portanto, há uma forte tendência na valorização do trabalho interdisciplinar da Matemática para a interação entre os pares e a relação dialógica no contexto escolar, priorizando as atividades em grupo, a discussão e a construção coletiva e colaborativa dos resultados.

Dessa forma, é no próprio espaço da sala de aula que conhecimentos e saberes deverão ser ampliados, constituindo-se em conceitos matemáticos significativos. Quando a criança sente-se desafiada a pensar, a buscar uma resposta a partir de situaçóes próprias do universo infantil, há uma notável motivação, que é ao mesmo tempo envolta na fantasia e no encantamento (SMOLE, 2000).

Sob essa ótica, a literatura infantil atua como uma possibilidade didático-metodológica criativa e interdisciplinar na medida em que propicia à Matemática da Educação Infantil situações de aprendizagem significativas permeadas pelas histórias, pelas brincadeiras, pelo faz de conta. Diante disso, a autora diz que trabalhar a interdisciplinaridade entre Matemática e literatura infantil favorece o aprendizado das crianças, "pois em atividades desse tipo, os alunos náo aprendem primeiro a Matemática para depois aplicar na história, mas exploram a Matemática e a história ao mesmo tempo". Essa abordagem rompe com a visáo mecanicista e instrumental que se tem da Matemática, em que primeiro o aluno aprende um determinado conceito para depois aplicá-lo em uma situação-problema ou em uma série de atividades semelhantes que pouco exigem da sua capacidade de pensar, da lógica e da organização do pensamento (SMOLE, 2000, p. 68).

Para ela, o trabalho interdisciplinar entre a literatura infantil e a Matemática permite que a criança elabore diferentes estratégias na busca de soluçóes dos problemas, utilizando para isso "desenho, oralidade, dramatização e tentativa e erro" (SMOLE, 2000, p. 11). Por isso, em vez de restringir o trabalho da sala de aula aos cálculos aritméticos, aos numerais e a outros conteúdos presentes em livros e desvinculado do cotidiano, há uma valorização do imaginário infantil, privilegia-se a construção e elaboração dos saberes pautados na resolução de situaçôes-problemas. 
Com base nessa fundamentação teórica, a Educação Infantil é entendida como o contexto sociocultural dos primeiros anos de escolarização, quando o gosto pela Matemática se desenvolve, visto que é um momento importante para o desenvolvimento do prazer ou desprazer tanto pela leitura quanto pela Matemática, como afirmam Yunes e Pondé (1989):

O despertar do interesse pelos livros passa obrigatoriamente pelos primeiros anos e pela escolarização. As crianças que não puderem beneficiar-se desse estímulo estarão certamente prejudicadas em relação às demais que, pelo meio familiar e escolar, descobriram a leitura. Assim os adultos têm um papel decisivo na iniciação que poderá transformar-se em prazer ou desprazer quase que definitivos [...]. (YUNES; PONDÉ, 1989, p. 56)

O desenvolvimento infantil acontece a partir das relaçóes queas crianças estabelecem dialeticamente com o mundo, por isso o questionar, o observar, o interpretar, o interagir e o registrar os fatos devem indiscutivelmente fazer parte das atividades dessa fase de desenvolvimento (SMOLE, 2000). É nesse universo de possibilidades que a literatura infantil favorece e facilita o trabalho interdisciplinar, pois "permite à criança conviver com relação não passiva entre linguagem escrita e falada” (SMOLE, 2000, p. 67-68), possibilita a ordenação do pensamento por meio da criação e recriação de histórias, favorece as conexôes com o real e o imaginário. Na representação dos desenhos, são manifestadas "operaçôes mentais como imaginação, lembrança, sonho, observação, associação, relação, simbolização, estando por isso implícita ao desenho uma conversa entre o pensar e o fazer" (p. 87) e, dessa maneira, "a literatura aparece como um jogo, uma fantasia muito próxima ao real, uma manifestação do sentir e do saber, o que permite a ela inventar, renovar e discordar" (p. 67).

A utilização da literatura infantil de maneira interdisciplinar possibilita que passos importantes sejam dados em direção à formação de conceitos matemáticos, já que eles perpassam a mera memorização de dados, tão comum no ensino academicista da Matemática, desenvolvida na Educação Infantil mediante atividades isoladas, mecânicas e rotineiras. Certamente, essas experiências influenciam negativamente a relação da criança com a Matemática, gerando um sentimento de repulsa, o que em geral culmina em sérias dificuldades de aprendizagem retratadas nos dados estatísticos apresentados no início deste artigo. Diante dessa discussão, 
verifica-se que a literatura infantil pode mediar uma grande variedade de situaçóes didático-pedagógicas, instigando a criança a simular situaçôes do cotidiano, a conjecturar possibilidades, a estabelecer relaçóes e a desenvolver habilidades balizadoras para a formação dos conceitos matemáticos nos primeiros anos da escolarização.

\section{O professor e a formaçáo de conceitos matemáticos}

$\mathrm{Na}$ formação dos conceitos matemáticos na Educação Infantil mediada pela literatura, salienta-se o papel do professor como organizador e facilitador desse processo de ensino e aprendizagem, pois esse profissional pode "provocar pensamentos matemáticos através de questionamentos ao longo da leitura, ao mesmo tempo em que a criança se envolve com a história. Assim, a literatura pode ser usada como estímulo para ouvir, ler, pensar e escrever sobre Matemática" (SMOLE, 2000, p. 75).

Vygotsky (1996) diz que os conceitos são construçóes culturais internalizadas pelos indivíduos ao longo de seu processo de desenvolvimento. Portanto, um conceito náo deve ser usado simplesmente para definir algo ou alguma coisa, uma vez que ele está na essência do objeto que se revela a partir da aproximação, compreensão, problematização, significação e sistematização. Assim, formar conceitos é descobrir as relaçóes existentes na realidade e representá-las na consciência, dando sentido ao conhecimento. Nesta perspectiva, o aluno precisa aprender a pensar e a linguagem pode ser o meio para esse posicionamento.

Para Lipman (1995), é no processo de falar que o pensar é operado. Para que uma ação se concretize de forma consciente, deve passar primeiramente pela formação de conceitos para logo em seguida ser apropriada pelo sujeito, que só então saberá ser crítico e reflexivo diante do seu uso. Vygotsky (2009, p. 226) afirma que "o conceito surge quando uma série de atributos abstraídos torna a sintetizar-se, e quando a síntese abstrata assim obtida se torna forma basilar de pensamento com o qual a criança percebe e torna conhecimento da realidade que a cerca".

Sendo assim, formar conceitos matemáticos é descobrir as relaçôes existentes na realidade e representá-las na consciência, dando sentido ao conhecimento. Dessa forma, o livro literário tornar-se para o professor um profícuo recurso pedagógico-didático, visto que oferece inúmeras possibilidades do trabalho interdisciplinar na sala de aula, relacionando o 
ato de falar, de ouvir, de coleta de dados, de inferir e fazer conjecturas com a construção e a elaboração dos conceitos matemáticos.

De acordo com Smole (2000), os professores têm optado por elaborar um conjunto de açóes didático-pedagógicas que não apenas possibilitem aos alunos da Educação Infantil o desenvolvimento de noçóes e conceitos matemáticos, mas também valorizem integralmente a percepção do aluno. Utilizando-se desse parâmetro, a criança deve ser vista como alguém que tem ideias próprias, sentimentos, vontades, que está inserida num contexto sociocultural, que pode aprender Matemática e desenvolver suas diferentes competências cognitivas.

Para isso, as atividades que envolvem a construção dos conceitos matemáticos naEducação Infantil devem valorizar habilidades e competências que favoreçam a construção do conhecimento lógico-matemático, como coletar, organizar e descrever dados, pois durante a realização desse trabalho várias habilidades são desenvolvidas como, por exemplo, a exploração, a investigação, a conjectura e a comunicação, bem como a resolução de problemas. Nesse intento, nos Parâmetros Curriculares Nacionais (1997) há a seguinte discussão:

Resolver um problema pressupóe que o aluno: elabore um ou vários procedimentos de resoluçáo (como, por exemplo, realizar simulaçóes, fazer tentativas, formular hipóteses); compara seus resultados com os de outros alunos; valida seus procedimentos. Resolver um problema não se resume em compreender o que foi proposto e em dar respostas aplicando procedimentos adequados. Aprender a dar uma resposta correta, que tenha sentido, pode ser suficiente para que ela seja aceita e até seja convincente, mas náo é garantia de apropriação do conhecimento envolvido. Além disso, é necessário desenvolver habilidades que permitam pôr à prova os resultados, testar seus efeitos, comparar diferentes caminhos, para obter a solução. Nessa forma de trabalho, o valor da resposta correta cede lugar ao valor do processo de resolução. (BRASIL/RCNEI, 1997, p. 33)

Com esse intento, o professor deve planejar situaçóes de aprendizagem voltadas para a apreensão dos conteúdos, com atividades significativas e desafiadoras que estimulem cooperativamente a participação das crianças na elaboraçáo dos próprios métodos de resolução e na construção dos conhecimentos. Assim, a influência da ação mediadora do professor corrobora para que a sala de aula deixe de ser mero espaço formal do conhecimento para ser um ambiente dialógico e interativo. A esse respeito, Castro e Carvalho (2001, p. 130) acrescentam: 
O papel mediador do professor assume diferentes aspectos. É coordenador e problematizador nos momentos de diálogo em que os alunos organizam e tentam justificar suas ideias. Aproxima, cria pontes, coloca andaimes, estabelece analogias, semelhanças ou diferenças entre a cultura espontânea ou informal do aluno, de um lado, e as teorias e as linguagens formalizadoras da cultura elaborada, de outro, favorecendo o processo interior de ressignificação e retificação conceitual.

Somente dessa forma, o professor terá condições para auxiliar os seus alunos a formar uma nova representação social da Matemática para que eles levem a sua compreensão da vida cotidiana para a sala de aula (NUNES e BRYANT, 1997). E desta para a vida cotidiana (Smole, 2000), pois "vivendo o texto", de maneira interdisciplinar, a criança poderá "passar da condição de mero destinatário do discurso adulto a sujeito de sua própria história, realizando assim a meta a que paradoxalmente a educação se propóe" (YUNES e PONDÉ, 1989, p. 47).

Como destaca Regina Zilberman (2003, p. 16), a sala de aula apresenta todas as condiçóes para se tornar "um espaço privilegiado para o desenvolvimento do gosto pela leitura". Pode-se afirmar isso também em relação à Matemática. Portanto, esse é um espaço que possibilita cooperativamente situaçóes de aprendizagem diversificadas e trocas de experiências, pois as crianças trazem para a sala de aula as suas experiências do cotidiano. Outro ponto a salientar é que, nesse espaço, acontece a interaçáo entre educando e educador, e especialmente a interação entre criança e criança mediante o diálogo, as discussôes e o descobrir junto. E a partir dessas interaçóes, o professor terá possibilidades para observar e acompanhar sistematicamente, nas atividades propostas e sobretudo nas atividades espontâneas, o desenvolvimento dos conceitos matemáticos.

\section{Proposta didático-metodológica: trabalho interdisciplinar entre literatura infantil e matemática}

O planejamento de atividades interdisciplinares envolvendo a Matemática e a literatura infantil aponta para outra concepção de ensino, não mais pautada na compartimentalização dos saberes e conhecimentos em forma de disciplinas. Ela parte do pressuposto de que os alunos podem apreender e compreender os conceitos matemáticos a partir da utilização da literatura infantil, ouvindo as histórias, formulando e discutindo possi- 
bilidades de aprendizagem. Além de ser uma excelente oportunidade de relacionar as situaçôes do cotidiano dos alunos com seu aprendizado, esse trabalho interdisciplinar pode ainda mostrar que a matemática está presente em tantas outras situaçóes e possibilidades de atuaçáo, em outras disciplinas e temas, favorecendo significativamente a elaboração e a reconstrução dos conceitos matemáticos.

Quando os sujeitos do processo ensino e aprendizagem - educando e educador - discutem as histórias infantis, o professor tem o papel não apenas de ler para o aluno, mas também de criar situaçóes para ler com o aluno, que é entendido como sujeito ativo e participante no processo de ler e compreender. A leitura é enriquecida e o professor contribui para a formação de um leitor crítico e capacitado para agir na relação sujeito e meio social (SILVA; RÊGO, 2006). Para isso, o professor de Educação Infantil precisa promover um ambiente que favoreça o desenvolvimento da criança, "precisa valorizar, de forma articulada, a construçáo do conhecimento matemático, as brincadeiras infantis, os jogos, as experimentaçôes, as histórias infantis, para permitir uma introdução da criança ao pensar matemático, com motivação e sem rupturas" (BRASIL/SEB, 2009 p. 24).

De acordo com Secretaria de Educação Básica (SEB/2009), a literatura infantil - incluindo brincadeiras, lendas e parlendas - possui atributos significativos para a formação de conceitos matemáticos. No entanto, é fundamental que o professor saiba selecionar e avaliar as obras literárias para o planejamento e o desenvolvimento das atividades de maneira interdisciplinar. Nesse sentido, "uma boa exploração dos conteúdos matemáticos depende fortemente de seu planejamento, da preparaçáo antecipada do material necessário". Contudo, ressalta-se que essas iniciativas não invalidam "que os alunos também folheiem os livros e o leiam, e mesmo participem da preparação do material que vai ser utilizado" (p. 29).

Assim, diante de inúmeros livros literários que apresentam um leque de possibilidades para o desenvolvimento de atividades envolvendo a leitura, a escrita e a formação de conceitos matemáticos, citam-se alguns, no intuito de contribuir com o professor: em Aritmética da Emília (LOBATO, 2001) e Revolta dos números (MOTT, 1995), podem ser explorados os números a sequência numérica, a codificação e a quantificação dos números, antecessor e sucessor, as quatro operaçóes fundamentais - adição, subtração, multiplicação e divisão - e problemas de baixa complexidade, incluindo dezenas e dúzia. Nos livros De hora em hora (Rocha, 1998) e Armando e o 
tempo (GUTTMANN, 2005), há a possibilidade de se trabalhar as horas - tempo e espaço. Em Flicts (PINTO, 1984), Uma aventura no mundo de Tarsila (LEITÃO e DUARTE, 2004) e em As três partes (KOZMINSKI, 1999), podem ser trabalhadas as formas geométricas (sugere-se a construção de uma maquete simbolizando uma cidade - ruas, prédios, casas e praças e/ ou trabalhos com dobraduras ou brincadeiras utilizando os blocos lógicos). Nesse sentido, os PCN (1997) apontam que, no planejamento das atividades explorando a geometria, o professor deve estimular os alunos a desenvolver certas habilidades e competências:

Capacidade de estabelecer pontos de referência em seu entorno, a situar-se no espaço, deslocar-se nele, dando e recebendo instruçôes, compreendendo termos como esquerda, direita, distância, deslocamento, acima, abaixo, ao lado, na frente, atrás, perto, para descrever a posiçáo, construindo itinerários. (BRASIL/PCN, 1997, p. 49)

Nessa perspectiva, os livros Quando comecei a crescer (ROCHA, 2003) e Tia Anacleta e sua dieta (ORTHOF, 1993) possibilitam o desenvolvimento de atividades envolvendo o sistema de medidas - tamanho, peso, (comprimento e quilograma), pois, para os $\mathrm{PCN}$, atividades com essa abordagem têm como objetivo "levar a criança a compreender o procedimento de medir, explorando para isso tanto estratégias pessoais quanto o uso de alguns instrumentos, como balança, fita métrica e recipientes de uso frequente" (BRASIL/PCN,1997, p. 49).

O livro Como se fosse dinheiro (ROCHA, 2004) favorece significativamente a formação de conceitos matemáticos. Nesse caso, no planejamento das atividades pedagógicas, o professor deve incluir a exploração do sistema monetário - valor de troca, valor financeiro, moeda nacional (sugerese a simulação de um mercadinho em que poderão ser exploradas outras habilidades - o cálculo mental, as quatro operaçóes, o troco, a negociação etc.). Os livros Dedo mindinho (MACHADO, 1999) e Um, dois, feijäo com arroz (PINTO, 2000) servem para o estudo de ordem numérica e sequência lógica, utilizando-se das parlendas.

Outro livro que também pode contribuir para a formação de conceitos matemáticos é As centopeias e os seus sapatinhos (CAMARGO, 1991). A história se desenvolve com a personagem principal, a centopeia, que necessitando de calçados novos vai a uma loja, onde é atendida por uma joaninha. Após subir e descer por diversas vezes as escadas para trazer sapatos 
para a centopeia, a joaninha fica muito cansada. Percebendo isso, a cliente decide voltar no dia seguinte. Nesse momento, a joaninha desmaia.

Diante desse enredo e utilizando da interdisciplinaridade, o professor pode promover inicialmente situaçóes-problema aos alunos: Quantos pés tem a centopeia? Quantos sapatos serão necessários para calçá-los? Quantos pares de sapatos poderão ser formados? O professor pode também explorar a leitura, propor situaçóes-problema envolvendo o conceito de dezenas, unidades, adição, subtração, multiplicação, divisão, contagem de números, sistema monetário brasileiro, troco, distância da casa da centopeia até a loja. Pode ainda problematizar situaçóes envolvendo o contexto do aluno como, por exemplo, o tamanho do pé da criança, quantos pés estão na sala de aula, quantos sapatos, quem calça menor ou maior número, quantos alunos usam tênis etc.

Essas situaçôes problematizadoras favorecem a mobilização dos saberes matemáticos, o desenvolvimento da perspicácia e da autonomia dos alunos, que terão de pensar, resolver situações e tomar decisões. Nesse momento, a mediação do professor é salutar para esclarecer as dúvidas e dificuldades que porventura surgirem. O professor, em sua ação pedagógica mediadora, promoverá "a confrontação das propostas dos alunos, ao disciplinar as condiçóes em que cada aluno pode intervir para expor sua solução, questionar, contestar. Nesse papel, o professor é responsável por arrolar os procedimentos empregados e as diferenças encontradas", poderá também "promover o debate sobre resultados e métodos, orientar as reformulaçôes e valorizar as soluçóes mais adequadas" (BRASIL/PCN, 1997, p. 31). Atuando assim, o professor favorecerá o raciocínio lógico das crianças; em outras palavras, contribuirá para a formação da autonomia e da criticidade do aluno.

\section{Consideraçóes finais}

Quando a escola e seus profissionais promovem um ambiente estimulador ao aprendizado, as crianças desenvolvem habilidades e competências essenciais à sua vida (COSTA, 2007). Os Parâmetros Curriculares Nacionais apontam diretrizes para o professor, o qual deve "planejar pedagogicamente a educação infantil, elegendo conteúdos a ensinar e suas didáticas, gerenciando o espaço escolar na educaçáo infantil, levando em conta o desenvolvimento e aprendizagem específicos nas faixas etárias de 0 a 3 anos e de 
4 a 6 anos" (BRASIL/MEC/SEMTEC, 2000, p. 73), a fim de favorecer o desenvolvimento da autonomia, entre outras competências cognitivas e sociais da criança.

O professor da Educação Infantil, no trabalho em sala de aula, atua como "mediador das relações entre as crianças e os diversos universos sociais nos quais elas interagem, possibilita a criação de condiçóes para que elas possam, gradativamente, desenvolver capacidades ligadas à tomada de decisóes, à construção de regras" (BRASIL/RCN, 1998b, p. 43).

No entanto, Silva e Rêgo (2006) chamam a atenção para um desafio que pode surgir quando os professores planejam atividades matemáticas fazendo uso da literatura infantil: a resistência. Eles relatam que inicialmente, na intervenção realizada por eles, os alunos mostraram resistência à proposta de desenvolver um ensino que articule Matemática e textos literários. Essa atitude dos estudantes pode ser decorrente dos hábitos de um ensino que não estabelece relaçóes entre as disciplinas escolares. Contudo, eles relatam que, no decorrer da pesquisa, essa resistência cedeu espaço à curiosidade e ao desejo de compreensão do texto, inclusive das ideias matemáticas, ocorrendo atitudes como leitura cautelosa e reflexão sobre as informaçóes e os conceitos expostos nos livros literários.

Por isso, a mediação do professor poderá colaborar para a promoção de um ambiente que estimule as reflexóes e os questionamentos dos alunos, para que façam as conexóes entre o imaginário e o real e criem estratégias para a resolução de problemas. Para que isso aconteça, existe a necessidade de seleção de conteúdo e planejamento para a ação pedagógica, a qual será favorecida pela interdisciplinaridade, nesse caso, entre a Matemática e a literatura infantil, pois concordamos com Cecília Meireles (1979, p. 28) ao afirmar que "a literatura não é, como tantos supóem, um passatempo. É uma nutrição". Essa "nutrição" favorece inúmeras possibilidades para se desenvolver a imaginação, a criatividade, a fantasia e diversas habilidades na criança, por meio do contar e recontar histórias, da leitura de imagens, da encenação e das brincadeiras.

Por meio da literatura infantil, as crianças terâo a capacidade de desenvolver habilidades de leitura e escrita, bem como a Matemática, habilidades básicas para que outras competências sejam também desenvolvidas. Isso evidencia a importância de se utilizar a interdisciplinaridade no trabalho pedagógico, especialmente nas disciplinas em que constantemente os alunos apresentam baixos índices de aproveitamento, como o raciocínio lógico 
matemático, a leitura e a escrita, pois "o caráter disciplinar do ensino formal dificulta a aprendizagem do aluno, não estimula ao desenvolvimento da inteligência, de resolver problemas e estabelecer conexóes entre os fatos, conceitos, isto é, de pensar sobre o que está sendo estudado" (FORTES, 2011, p. 3).

Nessa perspectiva, a formação de conceitos matemáticos na Educação Infantil não se restringe, portanto, à mera repetiçấo de traçados e contornos em cadernos ou em folhas xerocopiadas na ânsia de fazer com que as crianças construam esses conceitos. $\mathrm{O}$ professor pode propiciar a todas as crianças, desde bebês, o contato com a matemática mediante a exploração, a invenção do próprio modo de comunicação e relaçấo com as situaçóes do cotidiano. Por isso, o professor, utilizando a literatura infantil, permeada pela fantasia, imaginação e criatividade, mediará e desenvolverá situaçóes para que os conceitos matemáticos sejam verdadeiramente construídos.

\section{Referências}

ABRAMOVICH, Fanny. Literatura infantil: gostosuras e bobices. 5. ed. São Paulo: Scipione, 1997.

BRASIL. Ministério da Educaçáo e do Desporto. Referencial curricular para a educação infantil. Brasília: MEC/SEF, v. 1, Introdução. 1998a. Disponível em: <http://portal.mec.gov.br/seb/arquivos/pdf/rcnei_vol1.pdf>. Acesso em: 7 jul. 2012.

BRASIL. Ministério da Educação e do Desporto. Referencial curricular para a educação infantil. Brasília: MEC/SEF, v. 2, Formação pessoal e social. 1998b. Disponível em: <http://portal.mec.gov.br/seb/arquivos/pdf/ volume2.pdf $>$. Acesso em: 10 jun. 2012.

BRASIL. Ministério da Educação e do Desporto. Parâmetros Curriculares Nacionais: Matemática. Brasília, 1997. Disponível em: <http://portal.mec. gov.br/seb/arquivos/pdf/livro03.pdf>. Acesso em: 31 jan. 2012.

BRASIL. Ministério da Educação e do Desporto. Parâmetros Curriculares Nacionais: Matemática/terceiro e quarto ciclos do ensino fundamental/ Ensino de quinta a oitava séries. Brasília, MEC/SEF, 1998c. Disponível em: $<$ http://portal.mec.gov.br/seb/arquivos/pdf/matematica.pdf>. Acesso em: 31 jan. 2012. 
BRASIL. Ministério da Educação e do Desporto. MEC/SEMTEC. Proposta de Diretrizes para a Formação Inicial de Professores da Educação Básica, em Nivel Superior. Brasília, 2000.

BRASIL. Ministério da Educação e do Desporto. Secretaria de Educação Básica. Acervo complementar: as áreas do conhecimento nos dois primeiros anos de Ensino Fundamental. Brasília, 2009.

BRASIL. Ministério da Educação e do Desporto. Todos pela Educação. Avaliação Brasileira do Final do Ciclo de Alfabetização 2011. 2012. Disponível em: <http://www.todospelaeducacao.org.br/comunicacao-emidia/noticias/18375/prova-abc-traz-d>. Acesso em: maio 2012.

CAMARGO, Milton. As centopeias e os seus sapatinhos. São Paulo: Ática, 1991.

CASTRO, Amélia D. de; CARVAlHO, Anna M. P. de (Org.). Ensinar a ensinar: didática para a escola fundamental e média. São Paulo: Pioneira Thomson Learning, 2001.

COSTA, Marta Morais da. Metodologia do ensino da literatura infantil. Curitiba: Ibpex, 2007.

FAZENDA, Ivani. Interdisciplinaridade: história, teoria e pesquisa. 4. ed. Campinas: Papirus, 1999.

FORTES, Clarissa Corrêa. Interdisciplinaridade: origem, conceito e valor. 2011. Disponível em: <http://www.pos.ajes.edu.br/arquivos/ referencial_20120517101423.pdf>. Acesso em: 30 jul. 2012.

GARCIA, Joe. A interdisciplinaridade segundo os PCN. Revista de Educação Pública, Cuiabá, v. 17, n. 35, p. 363-378, set./dez. 2008. Disponível em: <http://132.248.9.1:8991/hevila/Revistadeeducacaopublica/2008/no35/1. pdf>. Acesso em: 30 jul. 2012.

GUTTMAM, Mônica. Armando e o tempo. 2. ed. São Paulo: Paulus, 2005. JAPIASSU, Hilton. Interdisciplinaridade e patologia do saber. Rio de Janeiro: Imago, 1976.

KOZMINSKI, Edson Luiz. As três partes. São Paulo: Ática, 1999.

LEITÃO, Mércia M.; DUARTE, Neide. Uma aventura no mundo de Tarsila. 3. ed. São Paulo: Editora do Brasil, 2004. 
LIPMAN, Matthew; SHARP, Ann. A comunidade de investigação e o raciocínio crítico. São Paulo: CBFC, 1995.

LOBATO, Monteiro. Aritmética da Emília. 29. ed. São Paulo: Editora Brasiliense, 2001.

MACHADO, Ana Maria. Dedo mindinho. São Paulo: Moderna, 1999.

MEIRELES, Cecília. Problemas da literatura infantil. São Paulo: Summus, 1979.

MOTT. Odett Barros. Revolta dos números. São Paulo: Ediçóes Paulinas, 1995.

NEUENFELDT. Adriano E. do. Matemática e literatura infantil: sobre os limites e possibilidades de um desenho curricular interdisciplinar. Dissertação (Mestrado) - Universidade de Santa Maria, Santa Maria, Rio Grande do Sul, 2006. Disponível em: <http://w3.ufsm.br/ppge/diss_adriano_06.pdf>. Acesso em: 30 jul. 2012.

NUNES, Terezinha; BRYANT, Peter. Crianças fazendo matemática. Tradução de Sandra Costa. Porto Alegre: Artes Médicas, 1997.

OLIVEIRA, Ramon de. Informática educativa: dos planos e discursos à sala de aula. Campinas: Papirus, 1997.

ORTHOF. Sylvia. Tia Anacleta e sua dieta. Sáo Paulo: Editora Paulinas, 1993. (Coleção Lua Nova).

PIAGET, Jean. Aprendizagem e conhecimento. In: PIAGET, P.; GRÉCO, P. Aprendizagem e conhecimento. Rio de Janeiro: Freitas Bastos, 1974.

PINTO, Ziraldo Alves. Flicts. São Paulo: Melhoramento, 1984.

PINTO, Ziraldo Alves. Um, dois, feijäo com arroz. São Paulo: Melhoramentos, 2000 .

ROCHA, Ruth. De hora em hora. 3. ed. São Paulo: Quinteto Editorial, 1998.

ROCHA, Ruth. Quando comecei a crescer. São Paulo: Ática, 2003. (Coleção Procurando Firme).

ROCHA, Ruth. Como se fosse dinheiro. São Paulo: FTD, 2004. 
ROSA, Roseli Scuinsani da. Piaget e a matemática. I Simpósio Nacional de Ensino de Ciência e Tecnologia - ISBN: 978-85-7014-048-7. 2009. Disponível em: <http://www.pg.utfpr.edu.br/sinect/anais/artigos/9\%20 Linguagemecognicaonoensinodecienciaetecnologia/>. Acesso em: 5 ago. 2012.

SANCHEZ, Jesús Nicasio Garcia. Dificuldades de aprendizagem e intervenção psicopedagógica. Porto Alegre: Artmed, 2004.

SILVA, Adelmo C. da; RÊGO, Rogéria G. do. Matemática e literatura infantil: um estudo sobre a formaçáo do conceito de multiplicação. In: BRITO, Márcia Regina Ferreira de (Org.). Solução de problemas e a matemática escolar. Campinas, SP: Alínea, 2006. p. 207-236.

SMOLE, Kátia C. Stocco. A matemática na educaçâo infantil: a teoria das inteligências múltiplas na prática escolar. Porto Alegre: Artmed, 2000.

VYGOTSKY, Lev S. Teoria e método em psicologia. São Paulo: Martins Fontes, 1996.

VYGOTSKY, Lev S. A construção do pensamento e da linguagem. Tradução de Paulo Bezerra. 2. ed. São Paulo: WMF, 2009.

YUNES, Eliana; PONDÉ, Gloria. Leitura e leituras da literatura infantil. São Paulo: FTD, 1989.

ZILBERMAN, Regina. A literatura infantil na escola. São Paulo: Global, 2003.

Recebido em: 20 set. 2012

Aceito em: 6 dez. 2012 